\title{
Density Functional Study of Nitroprusside: Mechanism of the Photochemical Formation and Deactivation of the Metastable States
}

\author{
M. BUCHS, C. A. DAUL, P. T. MANOHARAN, ${ }^{*}$ C. W. SCHLÄPFER \\ Département de Chimie, Université de Fribourg, CH-1700 Fribourg, Switzerland
}

Received 11 September 2001; Accepted 25 April 2002

DOI 10.1002/qua.10437

\begin{abstract}
In this article, we present a theoretical investigation about the mechanism of the photochemical formation and deactivation of the metastable states observed in nitroprusside ions. The quantum chemical calculations are based on density functional theory. The peculiar photochemical and photophysical behavior of this molecule has attracted chemists' interest for a while. Due to this interest, many details on the nature of nitroprusside's ground state and its two metastable states were known. However, a clear picture of the reaction pathways between the three minima on the ground-state potential energy curve was still missing. By studying the excited states corresponding to all three minima, we could set up, in this work, a model explaining the photochemistry and photophysics responsible for the population of the three different states on the ground-state potential energy curve. (c) 2002 Wiley Periodicals, Inc. Int J Quantum Chem 91: 418-431, 2003
\end{abstract}

Key words: DFT; nitroprusside; metastable states; potential energy curve

\section{Introduction}

The nitroprusside ion is an early bird to the understanding of all transition metal nitrosyl compounds and hence attracted the interests of chemists for over four decades. The crystal structure of sodium nitroprusside, $\mathrm{Na}_{2}\left[\mathrm{Fe}(\mathrm{CN})_{5} \mathrm{NO}\right] \cdot 2 \mathrm{H}_{2} \mathrm{O}$, was deter-

Correspondence to: C. A. Daul; e-mail: claude.daul@unifroch *On leave from ITT Madras, honorary Professor, INCASR, Bangalore. mined in 1963 by X-ray diffraction technique [1]. This sodium nitroprusside (SNP) compound known pharmacologically and commercially as nipride was earlier used as a powerful vasodilator and is in general used in treatments of hypertensive emergencies and severe cardiac failures. SNP can produce nitric oxide, which in turn activates guanylate cyclase. Guanylate cyclase increases the concentrations of cyclic guanosine monophosphate (GMP) in smooth muscle, leading to vasodilatation in veins and arteries [2].

In the early 1960s, SNP attracted the attention of chemists and physicists for several reasons: 
1. The $\left[\mathrm{Fe}(\mathrm{CN})_{5} \mathrm{NO}\right]^{2-}$ ion acts as model compound to study the chemical bonding of nitrosyl group to transition metal ions. Based on their properties and the results of calculations the $\left[\mathrm{Fe}(\mathrm{CN})_{5} \mathrm{NO}\right]^{2-}$ is best described as a $\mathrm{Fe}^{2+}\left(\mathrm{d}^{6}\right)$ coordinated by $5 \mathrm{CN}^{-}$and one $\mathrm{NO}^{+}$ligand. $\mathrm{NO}^{+}$has a strong crystal field potential, even stronger than $\mathrm{CN}^{-}$, due to $\pi$ back bonding and thus dominates the splitting of the $d$-orbitals. The most important feature of $\mathrm{NO}^{+}$as a ligand is the presence of low-lying $\pi^{*}$ orbitals centered on the $\mathrm{NO}^{+}$ligand. They lie between the $3 d(\pi)$ and $3 d(\sigma)$ shell of the central metal ion. This leads to low energy metal-to-ligand chargetransfer (MLCT) bands [3-6].

2. Nitroprusside can upon reduction depending on the $\mathrm{pH}$ of the medium [7] or on irradiation in the solid state [8] produce different species like $\left[\mathrm{Fe}(\mathrm{CN})_{5} \mathrm{NOH}\right]^{2-}$ and $\left[\mathrm{Fe}(\mathrm{CN})_{5} \mathrm{NO}\right]^{3-}$.

3. SNP is used as a Mössbauer reference standard because of its negative chemical shift as well as for its large quadrupole splitting.

4. Another interesting property of SNP is the occurrence of long-living metastable states, formed upon irradiation by blue light, with possible application to energy or information storage. The long-lived metastability of SNP states are converted back to the ground state by irradiation of red light. Phenomenologically, the situation is similar to the light-induced-excitedspin-state-trapping (LIESST) effect found in the mid-1980s by DeCurtins et al. [9].

It was subsequently discovered that similar longlived states are generated by irradiation of other nitrosyl complexes of nickel [10-12], ruthenium [13-15], osmium [16], or iron [17, 18]. In the case of SNP, two light-induced metastable states have been discovered $[9,19-23]$. They are produced by blue light irradiation and annihilated by red light irradiation. In crystalline SNP at temperatures below $140 \mathrm{~K}$, the metastable states have lifetimes greater than $10^{4} \mathrm{~s}$ [24]. Because of this property, this compound might be used as material for memory devices, in which information can be written by blue light and erased by red light, or energy storage and attracted therefore the interest of many researchers [25-27]. Despite extensive studies, the nature of the two metastable states has been for a long time been the subject of debate. In 1990, Güdel [28] pointed out that the lifetime of the metastable states is inconsistent with any one-electron transfer model and that either a large structural change or a multielectron promotion is required to explain the stability of the species [28]. Mössbauer [29] and EPR [30] spectroscopy indicate that both metastable states are diamagnetic. The geometries of the two metastable states of SNP and that of its ground state have been identified experimentally by $\mathrm{X}$-ray diffraction at $50 \mathrm{~K}$ by Carducci et al. [23]. The most important point to note is that the structural changes are confined to the Fe-N-O fragment as was predicted already by Manoharan and Gray [3]. In the GS (ground state) the Fe-N-O fragment is linear, with the iron bound to the nitrogen. The symmetry of the complex ion is close to $C_{4 v}$. One of the two metastable states has a linear Fe-O-N fragment. In this state the NO ligand is inverted. The iron is bound to the oxygen atom (isonitrosyl, $\eta^{1}$ ). This metastable state is in general labeled as MS1 in the literature. In the second metastable state, which is in the literature labeled as MS2 and has $C_{s}$ symmetry, the $\mathrm{NO}$ lies in a $\sigma_{v}$ plane of the $\mathrm{Fe}(\mathrm{CN})_{5}$ fragment and is bound side on $\left(\eta^{2}\right)$. The energy of the metastable states was determined by calorimetry and Raman experiments to lie $1.1 \mathrm{eV}$ above the ground state for MS1 and $1.0 \mathrm{eV}$ for MS2 [19, 24]. The reaction path from the GS via MS2 to MS1 corresponds to the nondissociative end-over linkage isomerization, proposed by Armor and Taube for the rotation of isotopically labeled $\mathrm{N}_{2}$, which is isoelectronic to $\mathrm{NO}^{+}$in $\left[\mathrm{Ru}\left(\mathrm{NH}_{3}\right)_{5} \mathrm{~N}_{2}\right] \mathrm{Br}_{2}$ [31]. Careful photochemical excitation and thermal relaxation studies allowed the determination of the activation energies for the thermal backreaction from MS1 over MS2 to the GS [21]. $\mathrm{E}_{\mathrm{a}} 1$ for the reaction step from MS1 to MS2 is $0.7 \mathrm{eV} ; \mathrm{E}_{\mathrm{a}} 2$ for the reaction from MS2 to the GS is smaller $(0.5 \mathrm{eV})$. As a consequence it is not possible to accumulate $\left[\mathrm{Fe}(\mathrm{CN})_{5} \mathrm{NO}^{2+}\right.$ in MS2 by the thermal backreaction from MS1 to the GS. Due to these properties it is not surprising that several theoretical attempts were made to study this complex by computational methods [12, 32]. They have shown that the GS and the two metastable states of SNP correspond to three minima on the ground-state potential energy surface. However, in these studies the excited states and the corresponding potential energy curves of the nitroprusside ion were not included. Because they are important with respect to the mechanism of the photochemical formation, we carried out a detailed investigation of the ground and excited states of nitroprusside ions by the same computational methods to get better insight into the mechanism of the photochemical excitation and relaxation reactions. 
TABLE I

\begin{tabular}{|c|c|c|c|}
\hline & LDA/VWN & GGA/B88P86 & Exp. (Ref. 23) \\
\hline $\mathrm{Fe}-\mathrm{N}$ & 1.616 & 1.642 & $1.6656(7)$ \\
\hline $\mathrm{N}-\mathrm{O}$ & 1.159 & 1.170 & $1.1331(10)$ \\
\hline $\mathrm{Fe}-\mathrm{C}_{\mathrm{ax}}$ & 1.915 & 1.957 & $1.9257(9)$ \\
\hline $\mathrm{Fe}-\mathrm{C}_{\mathrm{eq}}$ & 1.907 & 1.959 & $1.9310 / 1.9403(6)$ \\
\hline $\mathrm{C}_{\mathrm{ax}}-\mathrm{N}_{\mathrm{ax}}$ & 1.164 & 1.172 & $1.159(12)$ \\
\hline $\mathrm{C}_{e q}-\mathrm{N}_{\mathrm{eq}}$ & 1.166 & 1.173 & $1.1603 / 1.1622(8)$ \\
\hline $\mathrm{Fe}-\mathrm{C}_{\mathrm{ax}}-\mathrm{N}_{\mathrm{ax}}$ & 180.0 & 180.0 & 179.78(8) \\
\hline $\mathrm{Fe}-\mathrm{C}_{\mathrm{eq}}-\mathrm{N}_{\mathrm{eq}}$ & 175.0 & 175.0 & $178.34 / 176.49(6)$ \\
\hline $\mathrm{Fe}-\mathrm{N}-\mathrm{O}$ & 180.0 & 180.0 & $176.03(7)$ \\
\hline $\mathrm{N}-\mathrm{Fe}-\mathrm{C}_{\mathrm{ax}}$ & 180.0 & 180.0 & $176.63(4)$ \\
\hline $\mathrm{N}-\mathrm{Fe}-\mathrm{C}_{\mathrm{eq}}^{\mathrm{ax}}$ & 95.2 & 94.5 & $93.40 / 97.65(2)$ \\
\hline $\mathrm{C}_{\mathrm{eq}}-\mathrm{Fe}-\mathrm{C}_{\mathrm{eq}}$ (trans) & 169.6 & 171.1 & $168.91(3)$ \\
\hline $\mathrm{C}_{\mathrm{eq}}-\mathrm{Fe}-\mathrm{C}_{\mathrm{eq}}$ (cis) & 89.5 & 89.7 & $90.25 / 88.20(2)$ \\
\hline
\end{tabular}

\section{Computational Methods}

The ADF [33, 34] program package, which uses density functional theory (DFT) within the KohnSham formalism, has been employed in our calculations. The Vosko, Wilk, and Nusair (VWN) [35] functional for exchange and correlation energies was used as the local density approximation (LDA). The nonlocal corrections using the Becke exchange [36] and Perdew correlation (B88P86) [37] have been applied in all gradient-corrected calculations [generalized gradient approximations (GGA)]. Basis functions were taken from the program database. All atoms were described by a triple- $\zeta$ STO basis set and the core electrons of $\mathrm{Fe}(1 s-2 p), \mathrm{C}(1 s), \mathrm{N}(1 s)$, and $\mathrm{O}(1 s)$ were kept frozen. In the time-dependent DFT (TDDFT) [38] formalism, the calculations were performed with the RESPONSE module of the ADF program. The excitation energies and oscillator strengths have been computed using the iterative DAVIDSON method. In TDDFT, either the B88P86 functional or the asymptotically correct Van Leeuwen-Baerends potential (LB94) [39] have been used.

\section{Results and Discussion}

\section{GEOMETRY AND ELECTRONIC STRUCTURE OF THE GROUND STATE}

The most important structural parameters for the optimized geometry of $\left[\mathrm{Fe}(\mathrm{CN})_{5} \mathrm{NO}\right]^{2-}$ in its ground state and for an ideal $C_{4 v}$ symmetry are compared in Table I with those from the recent
X-ray crystal structure determination [23]. The symmetry of the complex ion in the solid is $C_{s^{\prime}}$ slightly distorted from $C_{4 v}$ most probably by packing effects. The calculated structure is in good agreement with the experimental ones obtained by X-ray diffraction [23]. The main features of agreement are: $\mathrm{r}(\mathrm{Fe}-\mathrm{N}) \ll \mathrm{r}\left(\mathrm{Fe}-\mathrm{C}_{\mathrm{ax}}\right)$ as well as $\mathrm{r}\left(\mathrm{Fe}-\mathrm{C}_{\mathrm{eq}}\right)$; $\mathrm{r}(\mathrm{N}-\mathrm{O})<$ $\mathrm{r}(\mathrm{C}-\mathrm{N})$; Fe being pushed out of the equatorial plane of the cyanides toward the $\mathrm{N}-\mathrm{O}$ group; and $\mathrm{r}(\mathrm{Fe}-$ $\left.\mathrm{C}_{\mathrm{eq}}\right)=\mathrm{r}\left(\mathrm{Fe}-\mathrm{C}_{\mathrm{ax}}\right)$. The LDA functional, which is known to overbind, gives shorter bond lengths whereas the B88P86 functional yields bond lengths that are slightly longer. However, differences between the optimized and experimental structures are small. The arithmetic average of the deviations is $1.90 \mathrm{pm}$ in the case of the LDA optimization, with a maximal error of $2.9 \%$. In the case of the GGA optimization, this average amounts to $2.15 \mathrm{pm}$, with a maximum error of $3.2 \%$.

On the whole, these results are satisfactory because errors of the same order of magnitude are common when the crystal environment is neglected. It is gratifying to note that the method of calculation yields the correct structure for the GS of the $\left[\mathrm{Fe}(\mathrm{CN})_{5} \mathrm{NO}\right]^{2-}$ ion.

Figure 1 shows the frontier molecular orbitals. Table II gives the energy and orbital composition of these orbitals, which determine most of the properties of the complex ion. The nitroprusside ion hence has a closed-shell ${ }^{1} \mathrm{~A}_{1}$ ground state, corresponding to $t_{2 g}^{6} e_{g}^{0}$ occupation of the $d$ shell of a $\mathrm{Fe}^{2+}\left(3 \mathrm{~d}^{6}\right)$ ion in octahedral symmetry. This is in agreement with the EPR inactivity in the ground state of the nitroprusside ion [30] and earlier pre- 


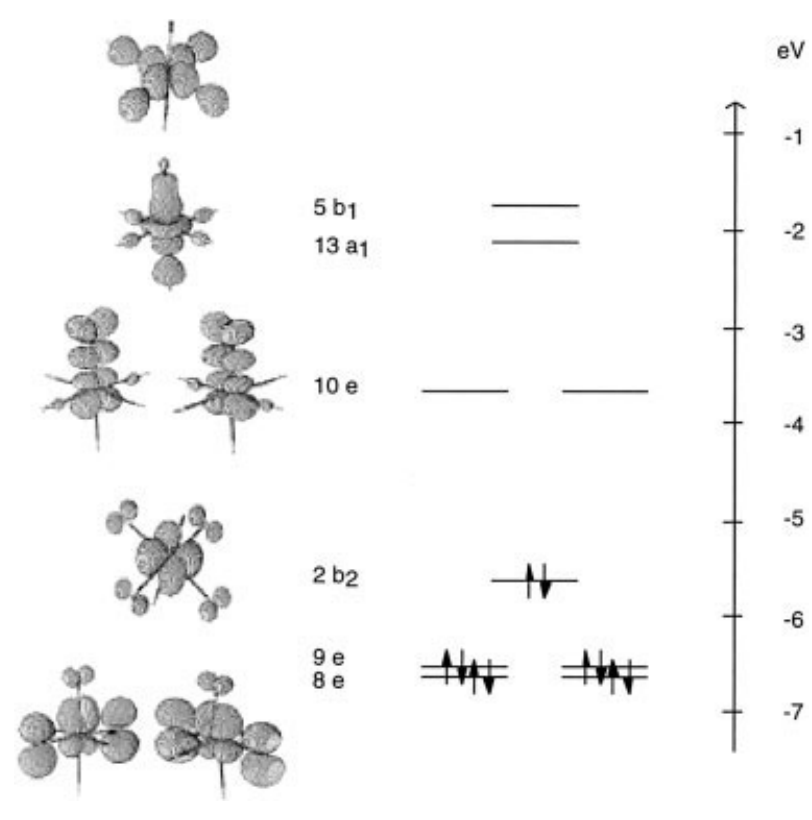

FIGURE 1. Frontier molecular orbitals of $\left[\mathrm{Fe}(\mathrm{CN})_{5} \mathrm{NO}\right]^{2-}$ in its ground-state geometry.

dictions based on Wolfsberg Helmholtz calculations $[3,5]$. In $C_{4 v}$ symmetry the degenerate $t_{2 g}$ metal orbitals are split into $b_{2}\left(d_{x y}\right)$ and e $\left(d_{x z}, d_{y z}\right)$ orbitals. The highest occupied molecular orbital (HOMO) is the $2 b_{2}$ orbital and has mainly a $d_{x y}$ metal character, with a large delocalization onto the in-plane $\pi^{*}$ orbitals of the four equivalent $\mathrm{CN}^{-}$ ligands of the same symmetry. The $d_{x z}$ and $d_{y z}$ orbitals have a bonding interaction with the $\pi^{*}$ orbitals of three $\mathrm{CN}^{-}$ligands and the $\pi^{*}$ orbital of the $\mathrm{NO}^{+}$(isoelectronic with the $\mathrm{CN}^{-}$) ligand. They lie lower in energy because $\mathrm{NO}^{+}$is a stronger $\pi$ acceptor ligand than $\mathrm{CN}^{-}$.
Table II further confirms the earlier results [3-5, 32] that the lowest unoccupied molecular orbital (LUMO), 10e, is a $\pi$ antibonding combination between the metal $d_{x z}, d_{y z}$ AOs, and the nitrosyl $\pi^{*}$ orbitals. The larger amplitude of this molecular orbital is on the $\pi_{x}$ and $\pi_{y}$ atomic orbitals of the $\mathrm{NO}$ group, indicating the strong ligand character. The energy of the $10 e$ orbitals lies between the $d$ $\pi^{*}\left(e, 2 b_{2}\right)$ and the $d-\sigma^{*}\left(13 a_{1}\right)$ metal orbitals. This was already predicted in earlier works [3-5, 32]. The degenerate $8 e$ orbital, consisting primarily of the metal $d_{x z}, d_{y z}$ and the $\pi^{*}$ orbitals of the NO ligand, is the bonding counterpart of $10 e$. The interaction is bonding between $\mathrm{Fe}$ and $\mathrm{N}$ and antibonding between $\mathrm{N}$ and $\mathrm{O}$. This interaction corresponds to the usual $\pi$-back bonding scheme used in describing the bonding of $\mathrm{NO}^{+}, \mathrm{CN}^{-}$, or $\mathrm{CO}$ with transition metals. This electronic structure, which is characteristic for all nitrosyl complexes [5, 32], is mainly due to the strong low-lying $\pi^{*}$ orbitals of the $\mathrm{NO}^{+}$ ligand, respectively its strong $\pi$ acceptor properties. The $9 e$ orbital is a symmetry-adapted linear combination of the $\mathrm{CN}^{-} \pi$ orbitals, with negligible metal and NO contributions.

\section{GEOMETRY AND ELECTRONIC STRUCTURE OF THE METASTABLE STATES}

The long-living metastable states of nitroprusside were discovered in 1977 [9]. As indicated in the introduction, Carducci et al. [23] determined the geometries of the two metastable states by X-ray diffraction technique at $50 \mathrm{~K}$. They are reached from the ground state by a rotation of the $\mathrm{NO}$ ligand. A rotation of the $\mathrm{NO}$ in one $\sigma_{v}$ plane $(x z$, respectively, $y z$ plane) of the $\mathrm{Fe}(\mathrm{CN})_{5}$ fragment by

TABLE II

Energies and orbital contributions (Fe3d, NO: N2p, O2p) to the frontier MOs of nitroprusside in the GS, symmetry $C_{4 v}$ (occupations in brackets).

\begin{tabular}{|c|c|c|c|c|c|c|c|c|c|c|}
\hline & $\operatorname{Fe}\left(d_{x 2-y 2}\right)$ & $\mathrm{Fe}\left(d_{z 2}\right)$ & $\mathrm{Fe}\left(d_{x y}\right)$ & $\mathrm{Fe}\left(d_{x z}\right)$ & $\mathrm{Fe}\left(d_{y z}\right)$ & $N\left(p_{x}\right)$ & $\mathrm{N}\left(p_{y}\right)$ & $O\left(p_{x}\right)$ & $\mathrm{O}\left(p_{y}\right)$ & $E(\mathrm{eV})$ \\
\hline $5 b_{1}(0)$ & $50 \%$ & $0 \%$ & $0 \%$ & $0 \%$ & $0 \%$ & $0 \%$ & $0 \%$ & $0 \%$ & $0 \%$ & -1.71 \\
\hline $13 a_{1}(0)$ & $0 \%$ & $49 \%$ & $0 \%$ & $0 \%$ & $0 \%$ & $0 \%$ & $0 \%$ & $0 \%$ & $0 \%$ & -2.10 \\
\hline $10 e_{\theta}(0)$ & $0 \%$ & $0 \%$ & $0 \%$ & $0 \%$ & $27 \%$ & $0 \%$ & $45 \%$ & $0 \%$ & $24 \%$ & -3.66 \\
\hline $10 e_{\varepsilon}(0)$ & $0 \%$ & $0 \%$ & $0 \%$ & $27 \%$ & $0 \%$ & $45 \%$ & $0 \%$ & $24 \%$ & $0 \%$ & -3.66 \\
\hline $2 b_{2}(2)$ & $0 \%$ & $0 \%$ & $69 \%$ & $0 \%$ & $0 \%$ & $0 \%$ & $0 \%$ & $0 \%$ & $0 \%$ & -5.63 \\
\hline $9 e_{\theta}(2)$ & $0 \%$ & $0 \%$ & $0 \%$ & $0 \%$ & $3.3 \%$ & $0 \%$ & $0 \%$ & $0 \%$ & $0 \%$ & -6.53 \\
\hline $9 e_{\varepsilon}(2)$ & $0 \%$ & $0 \%$ & $0 \%$ & $3.3 \%$ & $0 \%$ & $0 \%$ & $0 \%$ & $0 \%$ & $0 \%$ & -6.53 \\
\hline $8 e_{\theta}(2)$ & $0 \%$ & $0 \%$ & $0 \%$ & $0 \%$ & $28 \%$ & $0 \%$ & $6 \%$ & $0 \%$ & $8 \%$ & -6.59 \\
\hline $8 e_{\varepsilon}(2)$ & $0 \%$ & $0 \%$ & $0 \%$ & $28 \%$ & $0 \%$ & $6 \%$ & $0 \%$ & $8 \%$ & $0 \%$ & -6.59 \\
\hline
\end{tabular}


${ }_{N C}=\left.\right|_{C N} ^{N}<C N$

GS

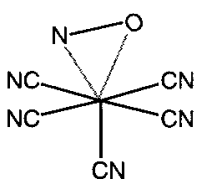

MS2

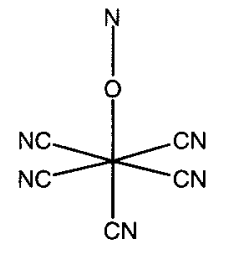

MS1
FIGURE 2. Structure of the GS, MS1, and MS2 of the nitroprusside ion.

ca. $100^{\circ}$ leads to the metastable state MS2. In MS2 the NO ligand is side bound to the Fe(II). The symmetry of MS2 is lowered to $C_{s}$. Further rotation by $80^{\circ}$ leads to the metastable state MS1. In MS1 the $\mathrm{NO}^{+}$is bound by the $\mathrm{O}$ to the $\mathrm{Fe}(\mathrm{II})$ in a linear Fe-O-N arrangement. The symmetry of MS1 is identical to the one of the GS, $C_{4 v}$. The structures of the GS and of the two metastable states of nitroprusside ions are depicted in Figure 2. The small difference in the electron density on the $\mathrm{N}$ and $\mathrm{O}$ of the $\mathrm{NO}^{+}$ligand made it hard to identify the structure of MS1 unambiguously [23]. Our calculations confirmed that both metastable MS1 and MS2 correspond to a minimum on the ground-state potential energy surface. This was already shown in earlier theoretical studies [12, 32]. The optimized structural parameters compared to the experimental one are given in Tables III and IV for both metastable states.

In the case of the metastable state MS1 with $C_{4 v}$ symmetry, we obtained a good agreement between the experimental and calculated structures (Table III). The averaged deviation is $1.75 \mathrm{pm}$ for bond lengths, with a maximal error of $2.3 \%$ in the case of the LDA optimization. In the case of the GGA optimization, the mean deviation drops to $1.05 \mathrm{pm}$, with a maximum error of $1.4 \%$. The calculated energy difference between the ground state and MS1 is $1.608 \mathrm{eV}$, in good agreement with the value of $1.677 \mathrm{eV}$ obtained by Delley et al. [32]. The experimental value reported in the literature is $1.1 \mathrm{eV}$ [19].

For the metastable state MS2 with $C_{s}$ symmetry, the mean deviation between optimized and experimental bond lengths is $5.63 \mathrm{pm}$ when using the LDA functional, with a maximum of $4.2 \%$ of error (Table IV). The arithmetic average of the deviation is $4.48 \mathrm{pm}$, with a maximal error of $4.6 \%$ for GGA. The angle Fe-N-O is $80.53^{\circ}$ (LDA) or $82.22^{\circ}$ (GGA), in good agreement with the experimental value of $82.0^{\circ}$ (cf. Table IV). The results of the calculation predicts MS2 somewhat more stable than MS1, in agreement with the experimental result. The calculated energy difference between the ground state and MS2 is $1.421 \mathrm{eV}$ as compared to $1.368 \mathrm{eV}$ obtained by Delley et al. [32]. The experimental value reported in the literature is $1.0 \mathrm{eV} \mathrm{[19].}$

The complete composition and the energies of the frontier orbitals of both MS1 and MS2 are given in Tables V and VI, respectively. The GS and the two metastable states have a closed-shell ground state, ${ }^{1} \mathrm{~A}_{1}$. The electronic structure of MS1 is similar to the one of the ground state. The HOMO in MS1 is $2 b_{2}$ with the major contribution steming from the $d_{x y}$ atomic orbital of the iron atom. In MS2, $C_{s}$ symmetry, this orbital becomes $12 \mathrm{a}^{\prime \prime}$. The HOMO is not involved in any major interactions with the $\mathrm{NO}^{+}$ligand. Hence, its energy is similar in the GS and the two metastable states. The occupied metal

TABLE III Most important structural parameters of the $\mathrm{MS} 1$ of $\left[\mathrm{Fe}(\mathrm{CN})_{5} \mathrm{NO}^{2-}\right.$ (length in $\AA$, angle in ${ }^{\circ}$ ).

\begin{tabular}{lccc}
\hline MS1 & LDA (VWN) & GGA (B88P86) & Exp. (Ref. 23) \\
\hline $\mathrm{Fe}-\mathrm{O}$ & 1.697 & 1.731 & $1.715(5)$ \\
$\mathrm{O}-\mathrm{N}$ & 1.151 & 1.163 & $1.140(7)$ \\
$\mathrm{Fe}-\mathrm{C}_{\mathrm{ax}}$ & 1.875 & 1.921 & $1.926(6)$ \\
$\mathrm{Fe}-\mathrm{C}_{\text {eq }}$ & 1.906 & 1.960 & $1.940 / 1.947(4)$ \\
$\mathrm{C}_{\mathrm{ax}}-\mathrm{N}_{\mathrm{ax}}$ & 1.166 & 1.172 & $1.149(7)$ \\
$\mathrm{C}_{\text {eq }}-\mathrm{N}_{\text {eq }}$ & 1.168 & 1.175 & $1.154 / 1.161(4)$ \\
$\mathrm{Fe}-\mathrm{C}_{\mathrm{ax}}-\mathrm{N}_{\text {ax }}$ & 180.0 & 180.0 & $179.3(4)$ \\
$\mathrm{Fe}-\mathrm{C}_{\text {eq }}-\mathrm{N}_{\text {eq }}$ & 175.2 & 175.5 & $178.6 / 176.6(3)$ \\
$\mathrm{Fe}-\mathrm{O}-\mathrm{N}$ & 180.0 & 180.0 & $174.9(4)$ \\
$\mathrm{O}-\mathrm{Fe}-\mathrm{C}_{\mathrm{ax}}$ & 180.0 & 180.0 & $177.1(3)$ \\
$\mathrm{O}-\mathrm{Fe}-\mathrm{C}_{\text {eq }}$ & 94.3 & 172.6 & $93.0 / 97.0(2)$ \\
$\mathrm{C}_{\text {eq }}-\mathrm{Fe}-\mathrm{C}_{\text {eq }}$ (trans) & 171.3 & 89.8 & $170.0(3)$ \\
$\mathrm{C}_{\text {eq }}-\mathrm{Fe}-\mathrm{C}_{\text {eq }}$ (cis) & 89.7 & & $90.1(2) / 88.5(1)$ \\
\hline
\end{tabular}


TABLE IV Most important structural parameters of the MS2 of $\left[\mathrm{Fe}(\mathrm{CN})_{5} \mathrm{NO}^{2-}\right.$ (length in $\AA$, angle in ${ }^{\circ}$ ).

\begin{tabular}{lccc}
\hline MS2 & LDA (VWN) & GGA (B88P86) & Exp. (Ref. 23) \\
\hline Fe-N & 1.794 & 1.834 & $1.893(19)$ \\
Fe-O & 1.989 & 2.057 & $2.067(15)$ \\
$\mathrm{N}-\mathrm{O}$ & 1.204 & 1.210 & $1.14(2)$ \\
$\mathrm{Fe}-\mathrm{C}_{\mathrm{ax}}$ & 1.871 & 1.917 & $1.820(13)$ \\
$\mathrm{Fe}-\mathrm{N}-\mathrm{O}$ & 80.5 & 82.2 & $82.0(13)$ \\
$\mathrm{N}-\mathrm{Fe}-\mathrm{C}_{\mathrm{ax}}$ & 155.6 & 155.3 & $158.7(6)$ \\
\hline
\end{tabular}

orbitals mainly involved in interactions with the $\mathrm{NO}^{+}$ligands are the degenerate pair $d_{x z}$ and $d_{y z}(8 e$ in the ground state and $9 e$ in MS1). In both the GS and MS1 there is a strong $\pi$ backbonding interaction with the $\pi^{*}$ orbital of $\mathrm{NO}^{+}$. The corresponding anti bonding $\mathrm{MO}$ is the LUMO 10e with dominant $\mathrm{NO}^{+} \pi^{*}$ character (see Fig. 3). For MS2, with $C_{s}$ symmetry, only one $3 d$ orbital of the degenerate pair, $d_{x z}$, interacts strongly with the $\pi^{*}$ orbital of $\mathrm{NO}^{+}$if the rotated $\mathrm{NO}^{+}$lies in the $\mathrm{xz}$ plane. The MO showing this interaction is $24 a^{\prime}$. This interaction is responsible for the side on binding of the $\mathrm{NO}^{+}$. The corresponding antibonding combination is $26 a^{\prime}$. The splitting of the bonding and antibonding combination, $8 e$ and $10 e$ in the GS, $9 e$ and 10e in MS1, and 24a and 26a in MS2, is a direct measure for this interaction. Figure 4 shows the energies of the MOs given in Tables II, V, and VI as a function of the NO rotation angle.

To get more insight into the ground-state reaction path between the ground state and MS2, respectively, MS1 we calculated the potential energy curve along the rotation of the $\mathrm{NO}^{+}$ligand. The points have been obtained varying the rotation an- gle stepwise. At each step a geometry optimization was carried out relaxing all internal coordinates with the exception of the $\mathrm{NO}^{+}$rotation angle. Figure 3 shows the energy profile as a function of the rotation angle. The minima at 0 , ca. 100 , and $180^{\circ}$ characterize the ground state, MS2, and MS1, respectively. The maxima at ca. 70 and $140^{\circ}$ correspond to the transition states along the reaction coordinate.

The activation energies for the thermal backreaction from the metastable states to the ground states are also known [25]. $E_{a} 1$, the activation energy for the reaction from MS1 to MS2, was found to be $0.7 \mathrm{eV}$, and $E_{a} 2$, the activation energy for the reaction of MS2 to the ground state, is $0.5 \mathrm{eV}$. Our calculation, yields 1.19 and $0.39 \mathrm{eV}$ for $E_{a} 1$ and $E_{a} 2$, respectively, in reasonable agreement with the experimental results. Especially conforting is that the calculation gives the correct order $E_{a} 1>E_{a} 2$. Comparing Figures 3 and 4 , it is obvious that the main contribution to the shape of the GS potential function is the interaction of the nitrosyl $\pi^{*}$ orbitals with the occupied $3 d_{x z}$ orbital of iron. This overlap has a maximum for a Fe-N-O angle

TABLE V

Energies and orbital contributions (Fe3d, NO: N2p, O2p) to the frontier MOs of nitroprusside in MS1, symmetry $C_{4 v}$ (occupations in brackets).

\begin{tabular}{rrrrrrrrrrr}
\hline & $\mathrm{Fe}\left(d_{x 2-y 2}\right)$ & $\mathrm{Fe}\left(d_{z 2}\right)$ & $\mathrm{Fe}\left(d_{x y}\right)$ & $\mathrm{Fe}\left(d_{x z}\right)$ & $\mathrm{Fe}\left(d_{y z}\right)$ & $\mathrm{N}\left(p_{x}\right)$ & $\mathrm{N}\left(p_{y}\right)$ & $\mathrm{O}\left(p_{x}\right)$ & $\mathrm{O}\left(p_{y}\right)$ & $\mathrm{E}(\mathrm{eV})$ \\
\hline $5 b_{1}(0)$ & $50 \%$ & $0 \%$ & $0 \%$ & $0 \%$ & $0 \%$ & $0 \%$ & $0 \%$ & $0 \%$ & $0 \%$ & -1.60 \\
$13 a_{1}(0)$ & $0 \%$ & $53 \%$ & $0 \%$ & $0 \%$ & $0 \%$ & $0 \%$ & $0 \%$ & $0 \%$ & $0 \%$ & -2.38 \\
$10 e_{\theta}(0)$ & $0 \%$ & $0 \%$ & $0 \%$ & $0 \%$ & $25 \%$ & $0 \%$ & $47 \%$ & $0 \%$ & $28 \%$ & -4.46 \\
$10 e_{\varepsilon}(0)$ & $0 \%$ & $0 \%$ & $0 \%$ & $25 \%$ & $0 \%$ & $47 \%$ & $0 \%$ & $28 \%$ & $0 \%$ & -4.46 \\
$2 b_{2}(2)$ & $0 \%$ & $0 \%$ & $71 \%$ & $0 \%$ & $0 \%$ & $0 \%$ & $0 \%$ & $0 \%$ & $0 \%$ & -5.54 \\
$9 e_{\theta}(2)$ & $0 \%$ & $0 \%$ & $0 \%$ & $0 \%$ & $43 \%$ & $0 \%$ & $18 \%$ & $0 \%$ & $4 \%$ & -6.30 \\
$9 e_{\varepsilon}(2)$ & $0 \%$ & $0 \%$ & $0 \%$ & $43 \%$ & $0 \%$ & $18 \%$ & $0 \%$ & $4 \%$ & $0 \%$ & -6.30 \\
$8 e_{\theta}(2)$ & $0 \%$ & $0 \%$ & $0 \%$ & $0 \%$ & $0 \%$ & $0 \%$ & $1 \%$ & $0 \%$ & $0.3 \%$ & -6.55 \\
$8 e_{\varepsilon}(2)$ & $0 \%$ & $0 \%$ & $0 \%$ & $0 \%$ & $0 \%$ & $1 \%$ & $0 \%$ & $0.3 \%$ & $0 \%$ & -6.55 \\
\hline
\end{tabular}


TABLE VI

Energies and orbital contributions (Fe3d, NO:N2p, O2p) to the frontier MOs of the nitroprusside in MS2, symmetry $C_{s}$, (occupations in brackets).

\begin{tabular}{rcrrrrrrrrrrr}
\hline & $\mathrm{Fe}\left(d_{x z-y z}\right)$ & $\mathrm{Fe}\left(d_{z 2}\right)$ & $\mathrm{Fe}\left(d_{x y}\right)$ & $\mathrm{Fe}\left(d_{x z}\right)$ & $\mathrm{Fe}\left(d_{y z}\right)$ & $\mathrm{N}\left(p_{x}\right)$ & $\mathrm{N}\left(p_{y}\right)$ & $\mathrm{N}\left(p_{z}\right)$ & $\mathrm{O}\left(p_{x}\right)$ & $\mathrm{O}\left(p_{y}\right)$ & $\mathrm{O}\left(p_{z}\right)$ & $\mathrm{E}(\mathrm{eV})$ \\
\hline $28 a^{\prime}(0)$ & $41 \%$ & $5 \%$ & $0 \%$ & $0.4 \%$ & $0 \%$ & $0 \%$ & $0 \%$ & $2 \%$ & $0 \%$ & $0 \%$ & $0.2 \%$ & -1.68 \\
$27 a^{\prime}(0)$ & $3 \%$ & $31 \%$ & $0 \%$ & $7 \%$ & $0 \%$ & $0.2 \%$ & $0 \%$ & $15 \%$ & $0 \%$ & $0 \%$ & $1 \%$ & -1.83 \\
$26 a^{\prime}(0)$ & $4 \%$ & $7 \%$ & $0 \%$ & $28 \%$ & $0 \%$ & $2 \%$ & $0 \%$ & $17 \%$ & $1 \%$ & $0 \%$ & $21 \%$ & -3.52 \\
$13 a^{\prime \prime}(0)$ & $0 \%$ & $0 \%$ & $10 \%$ & $0 \%$ & $9 \%$ & $0 \%$ & $56 \%$ & $0 \%$ & $0 \%$ & $26 \%$ & $0 \%$ & -4.19 \\
$12 a^{\prime \prime}(2)$ & $0 \%$ & $0 \%$ & $39 \%$ & $0 \%$ & $33 \%$ & $0 \%$ & $0.3 \%$ & $0 \%$ & $0 \%$ & $0.3 \%$ & $0 \%$ & -5.47 \\
$11 a^{\prime \prime}(2)$ & $0 \%$ & $0 \%$ & $21 \%$ & $0 \%$ & $30 \%$ & $0 \%$ & $6 \%$ & $0 \%$ & $0 \%$ & $10 \%$ & $0 \%$ & -5.88 \\
$25 a^{\prime}(2)$ & $0 \%$ & $0.5 \%$ & $0 \%$ & $0.4 \%$ & $0 \%$ & $0.6 \%$ & $0 \%$ & $3 \%$ & $0 \%$ & $0 \%$ & $1 \%$ & -6.21 \\
$10 a^{\prime \prime}(2)$ & $0 \%$ & $0 \%$ & $0 \%$ & $0 \%$ & $0 \%$ & $0 \%$ & $0.1 \%$ & $0 \%$ & $0 \%$ & $0.7 \%$ & $0 \%$ & -6.40 \\
$9 a^{\prime \prime}(2)$ & $0.1 \%$ & $0 \%$ & $0.1 \%$ & $0 \%$ & $0 \%$ & $0 \%$ & $0.1 \%$ & $0 \%$ & $0 \%$ & $0.1 \%$ & $0 \%$ & -6.70 \\
$24 a^{\prime}(2)$ & $0 \%$ & $0.6 \%$ & $0 \%$ & $8 \%$ & $0 \%$ & $2 \%$ & $0 \%$ & $6 \%$ & $0.8 \%$ & $0 \%$ & $7 \%$ & -6.74 \\
\hline
\end{tabular}

of 180,0 , and ca. $100^{\circ}$ (see Figs. IV and V). This corresponds to the angles observed in the GS, MS1, and MS2. The overlap nearly disappears for angles around 60 and $140^{\circ}$, where the nodal plane of the $d_{x z}$ orbital points to one of the lobes of the $\pi^{*}$ orbital of $\mathrm{NO}^{+}$as indicated by the small splitting between the corresponding MOs $24 a^{\prime}$ and $26 a^{\prime}$.

\section{GEOMETRY AND ELECTRONIC STRUCTURE OF THE EXCITED STATES}

For a detailed description of the photochemical pumping of $\left[\mathrm{Fe}(\mathrm{CN})_{5} \mathrm{NO}\right]^{2+}$ in the metastable states, it is necessary to investigate the potential energy surface of the excited states, too. This is easier to achieve

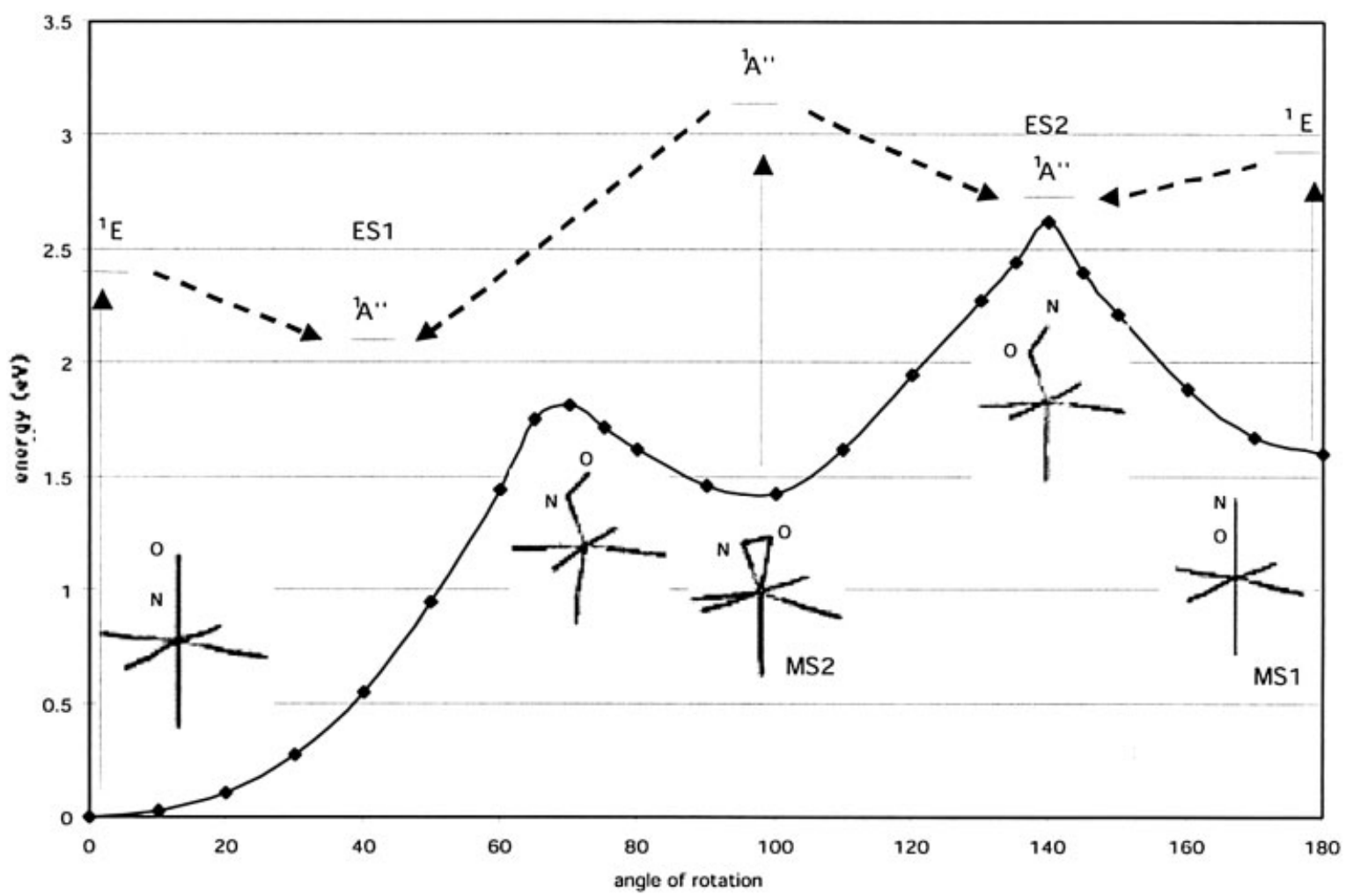

FIGURE 3. Potential energy of SNP as a function of the rotation angle of NO and energies of the excited states. Solid arrows denote photochemical excitation and broken arrows relaxation pathways. 


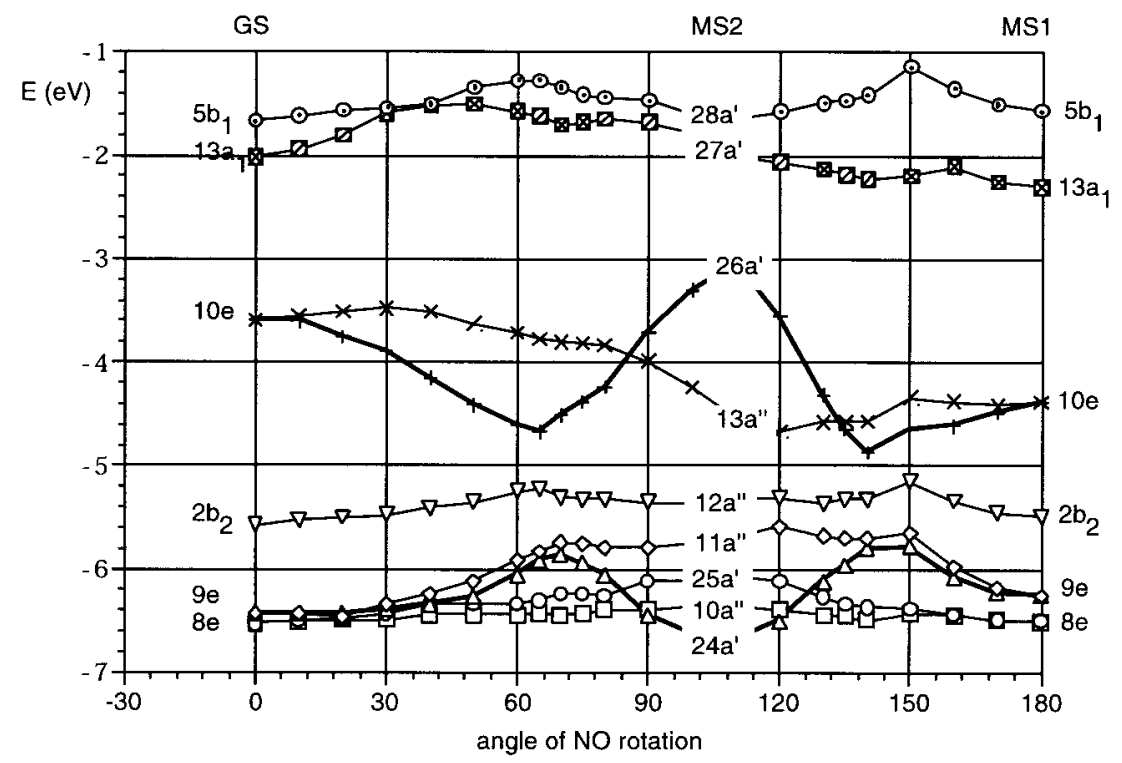

FIGURE 4. Energies of the frontier MOs as a function of the rotation angle of the NO ligand.

by computational methods than by experiments. Calculations of the excited-state energies of the nitroprusside ion have been carried out either in a time-dependent framework, using TDDFT [40], or time-independent framework, using the $\triangle \mathrm{SCF}$, difference self-consistent field method, as described in Ref. [41]. The calculated and observed excitation energies and the corresponding one-electron excitations for $\left[\mathrm{Fe}(\mathrm{CN})_{5} \mathrm{NO}\right]^{2-}$ are compiled in Table VII.

There are considerable differences between the energies obtained by $\triangle$ SCF and TDDTF, especially for MLCT transitions at low energies. For these types of transitions the calculation of the excitation
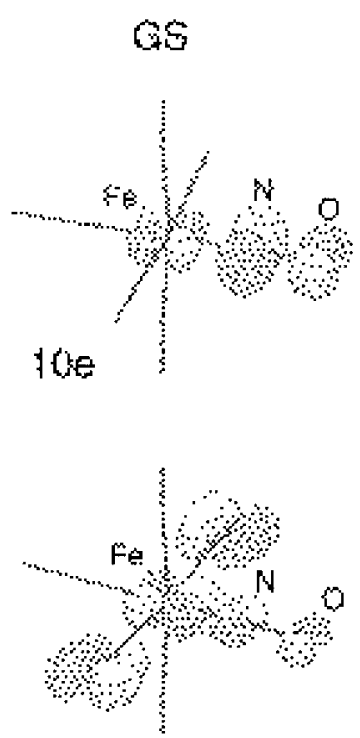

de
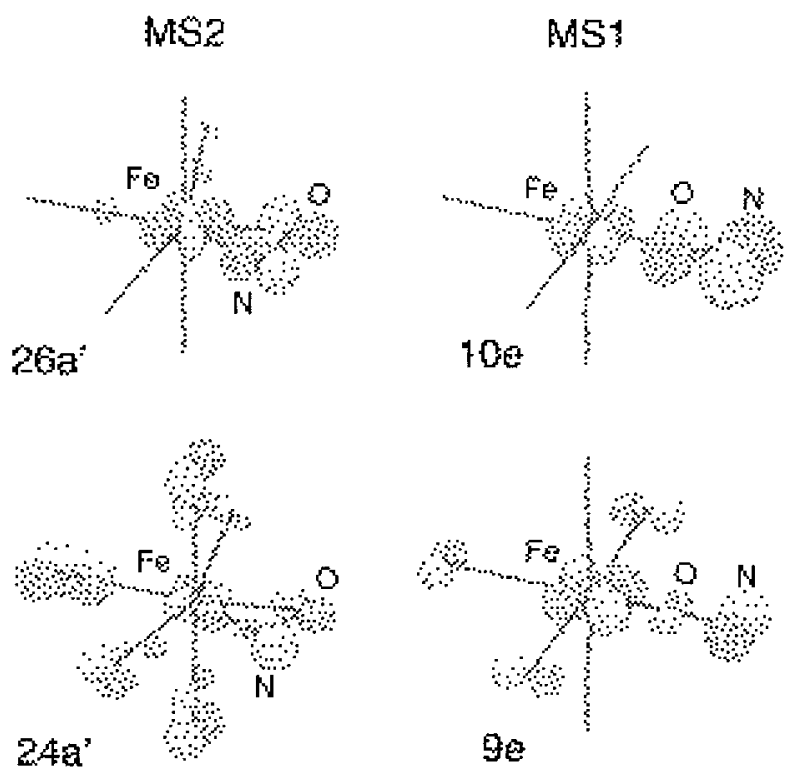<smiles>CC(C)C</smiles>

FIGURE 5. $\pi$ backbonding interactions in the GS, MS2, and MS1 of $\left[\mathrm{Fe}(\mathrm{CN})_{5} \mathrm{NO}\right]^{2-}$. 
TABLE VII

Lowest excitation energies (values in $\mathrm{cm}^{-1}$ ) in the $\mathrm{GS}$ of the $\left[\mathrm{Fe}(\mathrm{CN})_{5} \mathrm{NO}\right]^{2-}$ ion.

\begin{tabular}{|c|c|c|c|c|c|c|c|}
\hline & & & $\Delta S C F(G G A)$ & TDDFT (GGA) & TDDFT (LB94) & Exp. [3] & WHMO [3] \\
\hline \multirow[t]{2}{*}{$2 b_{2} \rightarrow 10 e$} & \multirow[t]{2}{*}{ MLCT } & ${ }^{1} \mathrm{E}$ & 18,601 & 17,341 & 15,431 & \multirow[t]{4}{*}{20,080} & \multirow[t]{4}{*}{20,540} \\
\hline & & ${ }^{3} \mathrm{E}$ & 16,923 & 14,661 & 12,628 & & \\
\hline \multirow{2}{*}{$2 b_{2} \rightarrow 13 a_{1}$} & \multirow[t]{2}{*}{ MC } & ${ }^{1} \mathrm{~B}_{2}$ & 32,658 & 32,098 & 31,635 & & \\
\hline & & ${ }^{3} \mathrm{~B}_{2}$ & 26,105 & 26,260 & 26,006 & & \\
\hline \multirow{2}{*}{$2 b_{2} \rightarrow 5 b_{1}$} & \multirow[t]{2}{*}{ MC } & ${ }^{1} A_{2}$ & 29,740 & 32,654 & 31,785 & \multirow[t]{10}{*}{30,300} & \multirow[t]{10}{*}{30,770} \\
\hline & & ${ }^{3} \mathrm{~A}_{2}$ & 25,359 & 29,320 & 28,562 & & \\
\hline \multirow[t]{8}{*}{$9 e \rightarrow 10 e$} & \multirow[t]{8}{*}{ LC } & ${ }^{1} A_{1}$ & 29,738 & 23,733 & 21,465 & & \\
\hline & & ${ }^{3} A_{1}$ & 22,496 & 22,690 & 19,430 & & \\
\hline & & ${ }^{1} A_{2}$ & 27,599 & 22,942 & 19,999 & & \\
\hline & & ${ }^{3} A_{2}$ & 26,003 & 22,918 & 19,967 & & \\
\hline & & ${ }^{1} \mathrm{~B}_{1}$ & 29,738 & 23,313 & 20,722 & & \\
\hline & & ${ }^{3} \mathrm{~B}_{1}$ & 22,496 & 22,804 & 19,437 & & \\
\hline & & ${ }^{1} \mathrm{~B}_{2}$ & 27,599 & 23,043 & 20,175 & & \\
\hline & & ${ }^{3} \mathrm{~B}_{2}$ & 26,003 & 22,917 & 19,664 & & \\
\hline \multirow[t]{8}{*}{$8 e \rightarrow 10 e$} & \multirow[t]{8}{*}{ MLCT } & ${ }^{1} A_{1}$ & 30,151 & 29,235 & 27,136 & \multirow[t]{10}{*}{25,380} & \multirow[t]{8}{*}{25,090} \\
\hline & & ${ }^{3} A_{1}$ & 29,603 & 17,790 & 16,144 & & \\
\hline & & ${ }^{1} A_{2}$ & 30,512 & 23,617 & 22,225 & & \\
\hline & & ${ }^{3} A_{2}$ & 30,429 & 23,616 & 22,223 & & \\
\hline & & ${ }^{1} \mathrm{~B}_{1}$ & 30,151 & 25,231 & 23,636 & & \\
\hline & & ${ }^{3} \mathrm{~B}_{1}$ & 29,603 & 21,398 & 20,208 & & \\
\hline & & ${ }^{1} \mathrm{~B}_{2}$ & 30,512 & 25,014 & 23,465 & & \\
\hline & & ${ }^{3} \mathrm{~B}_{2}$ & 30,429 & 21,452 & 20,304 & & \\
\hline \multirow{2}{*}{$9 e \rightarrow 13 a_{1}$} & \multirow[t]{2}{*}{ LMCT } & ${ }^{1} \mathrm{E}$ & 37,494 & 36,281 & 35,248 & & \\
\hline & & ${ }^{3} \mathrm{E}$ & 35,686 & 34,548 & 33,431 & & \\
\hline \multirow[t]{2}{*}{$9 e \rightarrow 5 b_{1}$} & \multirow[t]{2}{*}{ LMCT } & ${ }^{1} \mathrm{E}$ & 53,288 & 39,980 & 39,327 & & \\
\hline & & ${ }^{3} \mathrm{E}$ & 51,954 & 37,911 & 35,816 & & \\
\hline \multirow[t]{2}{*}{$8 e \rightarrow 13 a_{1}$} & \multirow[t]{2}{*}{ MC } & ${ }^{1} \mathrm{E}$ & 40,417 & 36,843 & 37,340 & \multirow[t]{2}{*}{37,800} & \multirow{2}{*}{37,750} \\
\hline & & ${ }^{3} \mathrm{E}$ & 39,025 & 35,354 & 35,530 & & \\
\hline \multirow[t]{2}{*}{$8 e \rightarrow 5 b_{1}$} & \multirow[t]{2}{*}{$\mathrm{MC}$} & ${ }^{1} \mathrm{E}$ & 44,131 & 41,099 & 40,574 & \multirow[t]{2}{*}{42,000} & \multirow[t]{2}{*}{40,900} \\
\hline & & ${ }^{3} \mathrm{E}$ & 42,276 & 38,417 & 38,043 & & \\
\hline
\end{tabular}

MC, metal centered; LC, ligand centered; LMCT, ligand-to-metal charge transfer.

energy is best carried out by the $\triangle \mathrm{SCF}$ method [42] as described in Ref. 43. This is clearly shown by a comparison between experimental and calculated energies. A similar observation was made for the lowest MLCT states of $\left[\mathrm{Ru}(\mathrm{bpy})_{3}\right]^{2+}$. For higherenergy states, for which the experimental transition energies have been determined experimentally, the TDDFT method gives results in slightly better agreement with experience.

The long-living metastable states of SNP have been observed when the molecule is excited below $150 \mathrm{~K}$ by radiation of a wavelength between 360 and $514 \mathrm{~nm}$ [9]. The wavelength dependence of the formation of the metastable states indicates that the first step of the reaction mechanism is an excitation of the charge-transfer transition $3 d \rightarrow \pi^{*}(\mathrm{NO})$. The experimental evidence combined with the results of the calculation of the transition energies of $\left[\mathrm{Fe}(\mathrm{CN})_{5} \mathrm{NO}^{2-}\right.$ in the GS indicate that the metastable state is reached after the promotion of one electron from the $2 b_{2}$ (Fe: $\left.3 d_{x y}\right)$ orbital to the $10 e\left(\pi^{*} \mathrm{NO}\right)$ orbital. The resulting excited state, $\left|2 b_{2}^{1} 10 e^{1}:{ }^{1} \mathrm{E}\right\rangle$, is degenerate and Jahn-Teller, or pseudo-RennerTeller, active considering only the Fe-N-O fragment. As a consequence, the symmetry of the system is spontaneously lowered from $C_{4 v}$ to $C_{s}$ and the ${ }^{1} \mathrm{E}$ state splits into two nondegenerate states, ${ }^{1} \mathrm{~A}^{\prime \prime}$ and ${ }^{1} \mathrm{~A}^{\prime}$. Pressprich et al. [22] predicted that the higher-energy state of these two is ${ }^{1} \mathrm{~A}^{\prime}$ and is nearly a linear Fe-N-O fragment. The lower-energy state is ${ }^{1} \mathrm{~A}^{\prime \prime}$ and has an eclipsed bent Fe-N-O geometry. The structure for both excited states was optimized. The most important structural parameters are given in Tables VIII and IX. As predicted by Pressprich et al., 
TABLE VIII

\begin{tabular}{|c|c|c|c|c|c|c|}
\hline$\left|{ }^{1} A^{\prime \prime}\right\rangle$ & $\operatorname{LDA}^{a}$ & $\mathrm{GGA}^{\mathrm{a}}$ & $G G A^{b}$ & GS/LDA & GS/GGA & MS2/GGA \\
\hline $\mathrm{Fe}-\mathrm{N}$ & 1.790 & 1.837 & 1.836 & 1.616 & 1.642 & 1.834 \\
\hline $\mathrm{N}-\mathrm{O}$ & 1.180 & 1.191 & 1.191 & 1.159 & 1.170 & 1.210 \\
\hline $\mathrm{Fe}-\mathrm{N}-\mathrm{O}$ & 141.1 & 141.5 & 141.7 & 180.0 & 180.0 & 82.2 \\
\hline $\mathrm{N}-\mathrm{Fe}-\mathrm{C}_{\mathrm{ax}}$ & 178.8 & 179.0 & 178.4 & 180.0 & 180.0 & 155.3 \\
\hline
\end{tabular}

${ }^{a}$ Reached by relaxation of the excited state $\left|2 b_{2}^{1} 10 e^{1} ;{ }^{1} \mathrm{E}\right\rangle$ of the GS.

${ }^{\mathrm{b}}$ Reached by relaxation of the excited state $\left|12 a^{\prime 1}{ }^{11} 26 a^{\prime 1} ;{ }^{1} \mathrm{~A}^{\prime \prime}\right\rangle$ of MS2.

the ${ }^{1} \mathrm{~A}^{\prime \prime}$ with the bent Fe-N-O is more stable than the ${ }^{1} \mathrm{~A}^{\prime}$ state. The calculated energy difference between ${ }^{1} \mathrm{~A}^{\prime \prime}$ and ${ }^{1} \mathrm{~A}^{\prime}$ is $0.2614 \mathrm{eV}$, that is, $2108 \mathrm{~cm}^{-1}$.

In addition, we computed the potential energy as a function of the NO rotation angle for ${ }^{1} \mathrm{~A}^{\prime \prime}$. For this the rotation angle has been kept fixed at different values between 180 and $120^{\circ}$, but the rest of the molecule, the $\mathrm{Fe}(\mathrm{CN})_{5}$ fragment, was free to relax at each step. Figure 6 shows the potential energy curve and gives a clear picture of both the size and extent of the Jahn-Teller stabilization energy for the excited $\left|12 a^{\prime 1}{ }^{1} 26 a^{\prime 1}:{ }^{1} \mathrm{~A}^{\prime \prime}\right\rangle$ state. The Jahn-Teller stabilization energy $\left(E_{\mathrm{JT}}\right)$ of the ${ }^{1} \mathrm{~A}^{\prime \prime}$ excited state obtained using the method of Daul et al. [44] is 0.3273 $\mathrm{eV}\left(2640 \mathrm{~cm}^{-1}\right)$.

The optimized structure of the lowest-energy excited state lies close to the transition state for the thermal reaction from the ground state to MS2, as can be seen in Figure 3 and in Table VIII. Deactivation from the relaxed excited state by a nonradiative process or a conical intersection [45] lead to a point on the ground-state potential energy surface, from where two competing relaxation channels are open, one back to the GS and the other to MS2. The fraction, which falls back into the ground state, is excited again. In this way, even if the transfer into MS2 is not efficient the system will finally be pumped into MS2.

TABLE IX

Geometry of the excited state $\left|12 a^{\prime \prime 1} 13 a^{\prime \prime} ;^{1} A^{\prime}\right\rangle$ reached by relaxation of the excited state $\mid 2 b_{2}^{1} 10 e^{1}$; $\left.{ }^{1} E\right)$ of the GS (bond lengths in $\AA$, angles in ${ }^{\circ}$ ).

\begin{tabular}{lllll}
\hline$\left.{ }^{1} \mathrm{~A}^{\prime}\right\rangle$ & LDA & GGA & GS/LDA & GS/GGA \\
\hline $\mathrm{Fe}-\mathrm{N}$ & 1.792 & 1.848 & 1.616 & 1.642 \\
$\mathrm{~N}-\mathrm{O}$ & 1.185 & 1.195 & 1.159 & 1.170 \\
$\mathrm{Fe}-\mathrm{N}-\mathrm{O}$ & 177.3 & 177.3 & 180.0 & 180.0 \\
$\mathrm{~N}-\mathrm{Fe}-\mathrm{C}_{\text {ax }}$ & 179 & 179 & 180 & 180 \\
\hline
\end{tabular}

The electronic structure of MS1 is close to the one of the ground state. The major difference is the smaller splitting between the HOMO $\left(2 b_{2}\right)$ and the LUMO (10e). The contribution of the $\mathrm{pN}$ orbital to $\pi^{*} \mathrm{MO}$ of NO is larger than the one of pO. Therefore, the $\pi$ backbonding overlap is less efficient if $\mathrm{NO}$ is $\mathrm{O}$ bound. As a consequence the lowest electronic transition of MS1 is at lower energy compared to the ground state.

Table $\mathrm{X}$ gives the excitation energies in MS1 calculated using TDDFT and $\triangle \mathrm{SCF}$. The first transition, corresponding to the promotion of an electron from $2 b_{2}\left(d_{x y}\right)$ into $10 e\left(\pi^{*} \mathrm{NO}\right)$ is 10,377 and 8322 $\mathrm{cm}^{-1}$ using the $\triangle \mathrm{SCF}$ and TDDFT methods, respectively. This transition has strong MLCT character as in the GS. The large difference between the result of the $\triangle \mathrm{SCF}$ calculation and the one of the TDDFT calculation is therefore no surprise. We assume that the energy obtained using $\triangle$ SCF represents the real transition energy much better as it was found for the ground state. Unfortunately, the absorption spectrum of the metastable state is not known for comparison. The only experimental observations are that the color of SNP in MS1 is blue-green and that irradiation with light in the range $600-1200 \mathrm{~nm}$ (8333-16,667 $\mathrm{cm}^{-1}$ ) depopulates MS1 [23].

As for nitroprusside in its GS, the lowest excited state of MS1 is the degenerated MLCT state, $\mid 2 b_{2}^{1}$

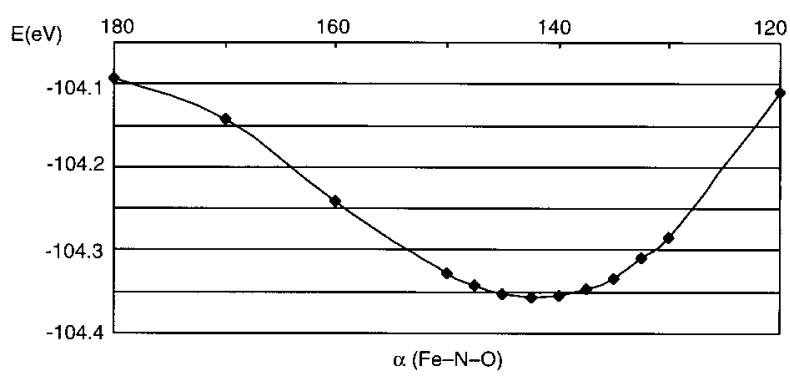

FIGURE 6. Jahn-Teller stabilization for the distortion $\left|2 b_{2}^{1}, 10 e^{1}:{ }^{1} \mathrm{E}\right\rangle \rightarrow\left|12 a^{\prime 1} 26 a^{\prime 1}:{ }^{1} A^{\prime \prime}\right\rangle$ state. 
TABLE $X$

Lowest excited state of $\left[\mathrm{Fe}(\mathrm{CN})_{5} \mathrm{NO}^{2-}\right.$ in MS1 (in $\mathrm{cm}^{-1}$ ).

\begin{tabular}{lccc}
\hline & $\Delta S C F(G G A)$ & TDDFT (LB94) \\
\hline $2 b_{2} \rightarrow 10 e$ & ${ }^{1} \mathrm{E}$ & 10,377 & 8,322 \\
& ${ }^{3} \mathrm{E}$ & 9,057 & 5,843 \\
\hline
\end{tabular}

$\left.10 e^{1} ;{ }^{1} \mathrm{E}\right\rangle$, which is Jahn-Teller active. The degenerate $\pi^{*}$-NO levels will split by a spontaneous JahnTeller distortion from $C_{4 v}$ to $C_{s}$, giving rise to two nondegenerate states, ${ }^{1} \mathrm{~A}^{\prime}$ and ${ }^{1} \mathrm{~A}^{\prime \prime}$. Of these two the ${ }^{1} \mathrm{~A}^{\prime \prime}$ state is the more stable for the same reason as in the GS. The Jahn-Teller distortion corresponds to a rotation of the NO ligand in a $\sigma_{v}$ plane. Energy minimization of the excited state shows that the $\mathrm{Fe}-\mathrm{O}-\mathrm{N}$ fragment is bent in the relaxed structure. The angle of rotation of the bound $\mathrm{NO}$ compared to the GS is ca. $140^{\circ}$, corresponding to a Fe-O-N angle of about the same size. Other important structural parameters of the relaxed excited state ${ }^{1} \mathrm{~A}^{\prime \prime}$ of MS1 are given in Table XI.

The Jahn-Teller stabilization energy $\left(E_{\mathrm{JT}}\right)$ of the excited ${ }^{1} \mathrm{~A}^{\prime \prime}$ state was calculated to $E_{\mathrm{JT}}=0.1445 \mathrm{eV}$ $\left(1165 \mathrm{~cm}^{-1}\right)$ using the same methodology as above [42]. With a Fe-O-N angle of about $140^{\circ}$, the excited ${ }^{1} \mathrm{~A}$ " state has a structure close to the one of the transition state between MS1 and MS2 (see Fig. 3). After deactivation to the ground-state potential energy surface two competing relaxation channels are open. The system relaxes either to MS2 or back to MS1. The fraction falling back to MS1 is again excited by the irradiation. By this mechanism MS2 is accumulated, even if the reaction path leading to MS2 is not efficient.

The investigation of the excited states of nitroprusside in the GS and MS1 allowed us to explain the mechanism for the photoinduced formation of MS2 starting from the GS or MS1. In both reactions the same principle is responsible. Upon excitation a

TABLE XI

Geometry of the excited state ES2 $\left|12 a^{\prime \prime 1} 26 a^{\prime 1} ;^{1} A^{\prime \prime}\right\rangle$ reached by relaxation of the excited state $\mid 2 b_{2}^{1} 10 e^{1}$; $\left.{ }^{1} E\right\rangle$ of MS1 (bond lengths in $\AA$, angles in ${ }^{\circ}$ ).

\begin{tabular}{lcc}
\hline & $\left|12 a^{\prime 1} 26 a^{\prime 1} ;{ }^{1} A^{\prime \prime}\right\rangle$ & MS1/GGA \\
\hline Fe-O & 2.025 & 1.731 \\
O-N & 1.190 & 1.163 \\
Fe-O-N & 139.8 & 180.0 \\
O-Fe-C & 175.9 & 180.0 \\
\hline
\end{tabular}

TABLE XII Lowest excited states of $\left[\mathrm{Fe}(\mathrm{CN})_{5} \mathrm{NO}^{2-}\right.$ in MS2 (in $\mathrm{cm}^{-1}$ ).

\begin{tabular}{cccc}
\hline & & $\Delta S C F(G G A)$ & TDDFT (LB94) \\
\hline $12 a^{\prime \prime} \rightarrow 13 a^{\prime \prime}$ & ${ }^{1} A^{\prime}$ & 11,033 & 8,691 \\
& ${ }^{3} A^{\prime}$ & 10,626 & 6,128 \\
$11 a^{\prime \prime} \rightarrow 13 a^{\prime \prime}$ & ${ }^{1} A^{\prime}$ & 14,170 & 16,819 \\
& ${ }^{3} A^{\prime}$ & 11,459 & 6,778 \\
$12 a^{\prime \prime} \rightarrow 26 a^{\prime}$ & ${ }^{1} A^{\prime \prime}$ & 15,933 & 16,325 \\
& ${ }^{3} A^{\prime \prime}$ & 12,568 & 12,776 \\
$25 a^{\prime} \rightarrow 13 a^{\prime \prime}$ & ${ }^{1} A^{\prime \prime}$ & 19,228 & 13,406 \\
& ${ }^{3} A^{\prime \prime}$ & 16,984 & 12,452 \\
$10 a^{\prime \prime} \rightarrow 13 a^{\prime \prime}$ & ${ }^{1} A^{\prime}$ & 23,030 & 14,355 \\
& ${ }^{3} A^{\prime}$ & 22,738 & 13,468 \\
& & & \\
\hline
\end{tabular}

degenerate excited state is reached, which relaxes with a rotation of the NO, respectively $\mathrm{ON}$ ligand, along the reaction coordinate in the direction of MS2. The wavelength of the excitation is in the violet to green region $(360-500 \mathrm{~nm})$ for the ground state, at lower energies, and in the red (600-1000 $\mathrm{nm})$ for MS1. The reason for the difference of excitation energies is the different extent of the $\pi$ backbonding in the ground state and MS1. To complete the description of the mechanism of the formation and decay of MS1, one has to explain the photoreactions of MS2 to the GS, respectively, to MS1. For this the excited states of MS2 have to be investigated. The electronic structure of MS2 is given in Table VI. The MO diagram can be read from Figure 5 at a value of $100^{\circ}$ for the rotation angle corresponding to the Fe-N-O angle of $80^{\circ}$ as found in MS2. The situation is not as clearcut as for the GS and MS1 because the number of orbitals and excited states to consider is larger because the degenerate MOs split upon the lowering of the symmetry. The calculated excitation energies for the lowest excited states of MS2 are collected in Table XII. Also in this case the $\triangle \mathrm{SCF}$ and TDDFT method was applied. The results obtained by the two methods differ considerably for certain excitations as observed for the excited states of GS and MS1. As discussed above, our expertise leads us to conclude that the reality is probably closer to the energies obtained by $\triangle \mathrm{SCF}$.

The only experimental information on the spectrum available is the observation that visible light (350-600 nm) converts MS2 to MS1 and that irradiation with light in the range of 600-1200 nm induces the transition from MS2 to the GS [23]. The most important promotion of an electron with re- 
spect to these reactions is from $12 a^{\prime \prime}$, the HOMO, into $26 a^{\prime}$. The wavelength for this transition is at approximately $16,000 \mathrm{~cm}^{-1}$, in the correct region of the spectrum. The energy of the orbital $26 a^{\prime}$, the antibonding combination of the $\pi^{*} \mathrm{NO}$ orbital with the $\mathrm{Fe} 3 d_{y z}$ orbital, is strongly influenced by rotation of the NO ligand (Fig. 5). The structure of this excited state was optimized. As expected, the major change of the geometry during the relaxation of this excited state is a rotation of the NO ligand. The $\mathrm{Fe}-\mathrm{N}$ interaction is intensified and the $\mathrm{Fe}-\mathrm{O}$ interaction weakened. In the optimized structure (Table VIII) the Fe-N-O angle is close to $140^{\circ}$. A comparison of the other structural parameters (Table VIII) and the electronic configuration of the relaxed excited state after the excitation of the GS shows that they are identical. As we have seen above, from this excited state the system has the possibility to relax into the GS. Hence, the promotion of an electron into from $12 a^{\prime \prime}$ to $26 a^{\prime}$ will open a photochemical relaxation channel from MS2 to the GS.

Finally, the photochemical reaction from MS2 to MS1 has to be considered. Inspection of the correlation diagram in Figure 5 shows that the energy of the $26 a^{\prime}$ orbital is close to a maximum at the structure of MS2. It is therefore reasonable to assume that the structure of MS2 and the energy of the Frank-Condon excited state lie close to the transition state between the relaxed excited states reached from the GS (angle of rotation $40^{\circ}$ ) and the relaxed excited state reached from MS1 (angle of rotation $140^{\circ}$ ). Hence, this state might relax in addition partially into the energy minimum between MS1 and MS2 of the excited state ${ }^{1} \mathrm{~A}^{\prime \prime}\left(\left|12 a^{\prime \prime 1}, 26 a^{\prime 1}\right\rangle\right)$ potential energy surface, especially if there is excess excitation energy. From this minimum the system will deactivate as discussed above either into MS1 or MS2.

\section{Conclusion}

Based on these results one can draw up the following two-step mechanism for the photochemical pumping of nitroprusside into MS1 (Fig. 4): First, the ion is excited by light between 360 and $500 \mathrm{~nm}$ into the lowest charge transfer excited state $\mid 2 b^{1}$ $\left.10 e^{1} ;{ }^{1} \mathrm{E}\right\rangle$. This degenerate excited state relaxes spontaneously driven by the Jahn-Teller stabilization energy to the excited state ES1. In this process the $\mathrm{NO}$ ligand is rotated by $40^{\circ}$. The symmetry descends from $C_{4 v}$ to $C_{s}$. This is followed by a radiationless deactivation of ES1 to the ground-state po- tential energy surface, close to the transition state of the thermal reaction from GS to MS2. From this point two relaxation channels are open, one back to the GS and the other to MS2. In the latter case the rotation angle of the NO ligand increases to about $100^{\circ}$. In this conformation a side on $\pi$ backbonding interaction between the $\mathrm{Fe}$ and the NO ligand (Fig. 5) stabilizes the system. Even if the relaxation to MS2 is not efficient compared to the backreaction, further illumination will pump the system gradually into MS2. In MS2 the nitroprusside can absorb light of the same wavelength as the GS. The vertical excitation of an electron from $12 a^{\prime \prime}$ to $26 a^{\prime}$ brings the system close to the transition state between ES1 and ES2 on the excited-state potential energy surface. At this point two relaxation channels are open for the excited state: one back to ES1 followed by relaxation to the GS or MS2 (see above) and the other to ES2, with a rotation of the NO ligand of about $140^{\circ}$ compared to the GS. After deactivation to the ground-state potential energy surface, now close to the transition state between MS2 and MS1, again two relaxation channels are open, one to back to MS2 and the other to MS1, with a rotation of NO by $180^{\circ}$. Also in this step, the ions, which relax back to the GS or MS2, are not lost. They are excited a second time, remain in the photochemical cycle, and end up finally in MS2. In MS2 the species are locked if the temperature is sufficiently low to inhibit the thermal backreaction because the absorption of light in the wavelength region of the excitation is weak.

The backreaction from MS1 to the ground state follows a completely analogous reaction path. Only the MLCT transition in MS1 is at lower energy due to the weaker $\pi$ backbonding capability of the Obound NO ligand. Light between 600 and $1000 \mathrm{~nm}$ is therefore sufficient to induce the cascade of reactions from MS1 over ES2 and MS2 and ES1 back to the GS.

The process is in many respects similar to the LIESST effect described by Gütlich and coworkers for iron(II) complexes [9]. Also in the LIESST mechanism a metastable state is reached after two consecutive excitations. The main difference, however, is that in the case of nitroprusside the spin state and the irreducible representation of GS, MS1, and MS2 are identical, whereas the spin state and the irreducible representation of GS, MS1, and MS2 are different in the LIESST system. This indicates that in nitroprusside the thermal backreactions are symmetry allowed, whereas they are forbidden by symmetry in the LIESST system. As mentioned above, 
this mechanism for the rotation of a diatomic ligand was already proposed 30 years ago by Armor and Taube to explain the observed inversion of isotopically labeled $\mathrm{N}_{2}$ in $\left[\mathrm{Ru}\left(\mathrm{NH}_{3}\right)_{5} \mathrm{~N}_{2}\right] \mathrm{Br}_{2}$. For the symmetrical ligand $\mathrm{N}_{2}$, which is isoelectronic to $\mathrm{NO}^{+}$, the reaction profile is of course symmetrical. An interesting, and to our knowledge open, question in this context is, however, if it is possible to characterize the intermediate with the $\mathrm{N}_{2}$-bound side on for the nondissociative end over isomerization mechanism.

In this work, we demonstrated the ability of DFT not only to reproduce experimental results but also to propose reasonable mechanisms for chemical processes that are difficult to obtain otherwise. Although it was possible to characterize the nature of the ground and the two metastable states of the nitroprusside ion by experimental and theoretical investigation, a consistent model explaining the photochemistry responsible for the population of MS1 by light in the violet-green region of the spectrum, and relaxation back to the GS state by light in the red region, has emerged after a detailed analysis of the electronic structure and the excited states of both the metastable states of this ion by computational methods. The mechanism proposed based on our calculation leads the experimentalist to plan new experiments, which allow confirming our conclusions. Obviously, the measurement of the quantum efficiency of the forward- and backreaction is especially interesting, as this will allow us to determine the efficiency of the different competing relaxation processes during the population and relaxation of MS1.

\section{ACKNOWLEDGMENT}

This work was supported by the Swiss National Science Foundation.

\section{References}

1. Manoharan, P. T.; Hamilton, W. C. Inorg Chem 1963, 2, 1043.

2. Stoelting, R. K. Pharmacology and Physiology in Anesthetic Practice; Lippincott-Raven: Philadelphia, 1999; p 315.

3. Manoharan, P. T.; Gray, H. B. J Am Chem Soc 1965, 87, 3340.

4. Gray, H. B.; Manoharan, P. T.; Pearlman, J.; Riley, R. F. Chem Commun 1965, 62

5. Manoharan, P. T.; Gray, H. B. Inorg Chem 1966, 5, 823.

6. Sweinhart, J. H. Coord Chem Rev 1967, 2, 385.

7. St. van Voorst, J. D. W.; Hümmerich, P. J Chem Phys 1966, 45, 3914.
8. Danon, J.; Muniz, R. P. A.; Caride, A. D. J Chem Phys 1966, 47, 1210.

9. Decurtins, S. U.; Gütlich, P.; Hasselbach, K. M.; Spiering, H.; Hauser, A. Inorg Chem 1985, 24, 2174.

10. Field, C. N.; Green, J. C.; Mayer, M.; Nasluzov, V. A.; Rösch, N.; Siggel, M. R. F. Inorg Chem 1996, 35, 2504.

11. Li, X.; Tse, J. S.; Bancroft, G. M.; Puddephatt, R. J.; Tan, K. H. Inorg Chem 1996, 35, 2515.

12. Coppens, P.; Fomitchev, D. V.; Carducci, M. D.; Culp, K. J Chem Soc Dalton Trans 1998, 865.

13. Fomitchev, D. V.; Coppens, P.; Li, T.; Bagley, K. A.; Chen, L.; Richter-Addo, G. B. Chem Commun 1999, 2013.

14. Morioka, Y.; Ishikawa, A.; Tomizawa, H.; Miki, E. J Chem Soc Dalton Trans 2000, 781.

15. Kawano, M.; Ishikawa, A.; Morioka, Y.; Tomizawa, H.; Miki, E.; Ohashi, Y. J Chem Soc Dalton Trans 2000, 2425.

16. Baraldo, L. M.; Bessega, M. S.; Rigotti, G. E.; Olabe, J. A. Inorg Chem 1994, 33, 5890.

17. Scheidt, R. W.; Duval, H. F.; Neal, T. J.; Ellison, M. K. J Am Chem Soc 2000, 122, 4651.

18. Cheng, L.; Novozhilova, I.; Kim, C.; Kovalevsky, A.; Bagley, K. A.; Coppens, P.; Richter-Addo, G. B. J Am Chem Soc 2000, $122,7142$.

19. Zöllner, H.; Krasser, W.; Woike, T.; Haussühl, S. Chem Phys Lett 1989, 161, 497.

20. Rüdlinger, M.; Schefer, J.; Chevrier, G.; Furer, N.; Güdel, H. U.; Haussühl, S.; Heger, G.; Schweiss, P.; Vogt, T.; Woike, T.; Zöllner, H. Z Phys B 1991, 83, 125.

21. Woike, T.; Krasser, W.; Zöllner, H.; Kirchner, W.; Haussühl, S. Z Phys D 1993, 25, 351.

22. Pressprich, M. R.; White, M. A.; Vekhter, Y.; Coppens, P. J Am Chem Soc 1994, 116, 5233.

23. Carducci, M. D.; Pressprich, M. R.; Coppens, P. J Am Chem Soc 1997, 119, 2669.

24. Zöllner, H.; Woike, T.; Krasser, W.; Haussühl, S. Z Kristallogr 1989, 188, 139.

25. Woike, T.; Kirchner, W.; Schetter, G.; Barthel, T.; Kim, H.; Haussühl, S. Opt Commun 1994, 106, 6.

26. Haussühl, S.; Schetter, G.; Woike, T. Opt Commun 1995, 114, 219

27. Güida, J. A.; Piro, O. E.; Aymonino, P. J. Inorg Chem 1995, 34, 4113 .

28. Güdel, H. U. Chem Phys Lett 1990, 175, 262.

29. Woike, T.; Kirchner, W.; Kim, H.; Haussühl, S.; Rusanov, V.; Angelov, V.; Ormandjiev, S.; Bonchev, T.; Schroeder, A. N. F. Hyperfine Interact 1993, 7, 265.

30. Terrile, C.; Nascimento, O. R.; Moraes, I. J.; Castellano, E. E.; Piro, O. E.; Güida, J. A.; Aymonino, P. J. Solid State Commun 1990, 73, 481.

31. Armor, J. N.; Taube, H. J Am Chem Soc 1970, 92, 2560.

32. Delley, B.; Schefer, J.; Woike, T. J Chem Phys 1997, 107, 10067.

33. ADF Program Package, version 2.0.1, Baerends, E. J.; Bérces, A.; Bo, C.; Boerrigter, P. M.; Cavallo, L.; Deng, L.; Dickson, R. M.; Ellis, D. E.; Fan, L.; Fischer, T. H.; Fonseca Guerra, C.; van Gisbergen, S. J. A.; Groeneveld, J. A.; Gritsenko, O. V.; Harris, F. E.; van den Hoek, P.; Jacobsen, H.; van Kessel, G.; Kootstra, F.; van Lenthe, E.; Osinga, V. P.; Philipsen, P. H. T.; 
Post, D.; Pye, C.; Ravenek, W.; Ros, P.; Schipper, P. R. T.; Schreckenbach, G.; Snijders, J. G.; Sola, M.; Swerhone, D.; te Velde, G.; Vernooijs, P.; Versluis, L.; Visser, O.; van Wezenbeek, E.; Wiesenekker, G.; Wolff, S. K.; Woo, T. K.; Tiegler, T.

34. Fonseca Guerra, C.; Snijders, J. G.; te Velde, G.; Baerends, E. J. Theor Chem Acc 1998, 99, 391.

35. Vosko, S. H.; Wilk, L.; Nusair, M. Can J Phys 1980, 58, 1200.

36. Becke, A. D. Phys Rev A 1988, 38, 3098.

37. Perdew, J. P. Phys Rev B 1986, 33, 8822.

38. Casida, M. E.; Jamorski, C.; Casida, K. C.; Salahub, D. R. J Chem Phys 1998, 108, 4439.

39. van Leeuwen, R.; Baerends, E. J. Phys Rev A 1994, 49, 2421.
40. Gross, E. K. U.; Dobson, J. F.; Petersilka, M. In: Nalewajski, R. F., ed. Density Functional Theory; Springer Verlag, Heidelberg, 1996.

41. Daul, C. A.; Doclo, G. K.; Stückl, A. C. In: Chong, D., ed. Recent Advances In Density Functional Theory, Vol. 2, University of British Columbia: Vancouver, 1997, p 61.

42. Daul, C.; Baerends, E. J.; Vernoijs, P. Inorg Chem 1994, 33, 3538.

43. Daul, C.; Buchs, M. (to be published).

44. Bruyndonckx, R.; Daul, C.; Manoharan, P. T.; Deiss, E. Inorg Chem 1997, 36, 4251.

45. Bernardi, F.; Olivucci, M.; Michl, J. A. Chem Soc Rev 1996, 321. 